\title{
The Waiting Room: \\ Neurological observations made outside the movement disorder specialist's consulting office
}

\author{
Rui Araújo MD; Bart P. van de Warrenburg MD, PhD; \\ Anthony E. Lang MD, FRCPC; Andrew J. Lees MD, FRCP, FMedSci; \\ Bastiaan R. Bloem, MD, PhD.
}

Rui Araújo, MD.
Neurology Department, Centro Hospitalar e Universitário de Coimbra
Coimbra, Portugal
rmma22@gmail.com

Bart P. van de Warrenburg, MD, PhD.

Radboud university medical centre

Donders Institute for Brain, Cognition and Behaviour

Department of Neurology;

Nijmegen, the Netherlands

bart.vandewarrenburg@radboudumc.nl

Anthony E. Lang, MD, FRCPC.

Morton and Gloria Shulman Movement Disorders Clinic and the Edmond J Safra

Program in Parkinson's Disease, Toronto Western Hospital

399 Bathurst Street, Toronto, Ontario

lang@uhnresearch.ca

Andrew J. Lees, MD, FRCP, FMedSci.

National Hospital, Queen Square

Reta Lila Weston Institute, University College London

andrew.lees@ucl.ac.uk

Bastiaan R. Bloem, MD, PhD. (corresponding author)

Radboud university medical centre

Donders Institute for Brain, Cognition and Behaviour

Department of Neurology

Nijmegen, the Netherlands

bas.bloem@radboudumc.nl

Running title: The Waiting Room

Title character count: 97

Number of references: 33

Number of tables: 1

Word count: 2895

Disclosures: There are no relevant disclosures.

Key words: Clinical Neurology; Examination; Movement Disorders; Waiting room 


\section{Abstract}

The neurological examination should always begin before the patient enters the doctor's office. Movement disorders in particular lend themselves to a spot diagnosis. In today's busy buzzing world, it would seem wasteful not to make use of the various diagnostic clues that can be picked up readily while the patient is still in the waiting room. We present several illustrative examples, drawn from the literature and from our own personal experience. These are divided according to the different waiting room "stages": the patient sitting in the waiting room, the response on being summoned to enter the consulting room - including rising from the chair, exchanging initial pleasantries and the way of walking. We also discuss the importance of paying attention to the patient's behaviour, clothing, posture, breathing patterns, facial expression and major gait abnormalities. 


\section{Introduction}

The "art of neurology" involves careful history taking and a detailed neurological assessment. Both are typically performed in the consulting room. But the neurological observation actually begins well before the patient has entered the physician's consulting room.

Three historical examples may serve to illustrate this. First, upon their initial entry into the United States of America, immigrants were initially brought to Ellis Island, where doctors of the US Public Health Department immediately began their observations while subjects climbed the famous staircase to the second floor where the formal inspection was going to take place. ${ }^{1}$ Staircase ascent can be very informative, offering useful insights into e.g. proximal leg weakness or dyspnoea. So, the first check for signs of physical disability had already taken place, even before the immigrants were aware of it. ${ }^{1}$ The second example is that of the fictional detective Sherlock Holmes, whose unfathomable powers of deduction were inspired by the Edinburg surgeon Joseph Bell. ${ }^{2}$ One illustrative anecdote describes how $\mathrm{Dr}$ Bell's legendary observational skills allowed him to diagnose a patient even before formally examining her, solely based on her accent, the red clay on her feet, as well as her dermatitis, which was considered unique to workers of a particular linoleum factory in England. ${ }^{3}$ As his pupil Sir Arthur Conan Doyle put it, through the words of Sherlock Holmes, "my method is based on the observation of trifles". ${ }^{4} \mathrm{~A}$ further example comes from James Parkinson's landmark Essay on the Shaking Palsy, published in 1817, and representing perhaps one of the most compelling illustrations of the importance of neurological observation outside the examination room. Specifically, James Parkinson picked up a range of clinical subtleties merely by watching people walking in the street. Indeed, three of the six patients he described were assessed in this fashion. ${ }^{5}$

Clinical medicine is riddled with such stories. A young woman carrying a cuddly toy while waiting for an EEG recording (the so-called "teddy bear sign") raises the possibility of non-organic epileptic seizures. ${ }^{6} \mathrm{~A}$ subtle sign, mostly of historical interest, of left-sided hemiparkinsonism is the "Andrade-Marsden-Rolex sign", where patients kept taking their Rolex (with automatic or self-winding mechanisms that depend on limb movements to wind) to repairers and they couldn't find anything wrong with it. Eventually, patients started wearing them on the right wrist instead of the more usual left wrist. ${ }^{7}$

Some patients "raise their game" when in the doctor's examination room, such as the patient with Parkinson's disease (PD), in whom freezing of gait or even shuffling of gait can be conspicuously absent when formally examined. ${ }^{8}$ Patients with Gilles de la Tourette syndrome (GTS), in whom tics can be temporarily suppressed, are best 
observed before or after the patient has left the consulting room. ${ }^{9}$ Observations of such patients in the waiting room (where they likely portray more spontaneous behaviour) can therefore yield very useful information. Another informative element is inconsistency over time, which is an important supportive diagnostic feature for functional movement disorders (FMD). ${ }^{10}$ This variability may be missed altogether if the observation is restricted to the examination room.

Therefore, being a "meeter" (someone who personally collects the patients from the waiting room) instead of a "buzzer" (someone who presses a buzzer on the office desk to call for the next patient) may thus give the physician an important diagnostic edge. ${ }^{11}$ With new cases, after going through the referring letter and before we see the patient, and even in the follow-up of complex patients where diagnostic uncertainty remains, it can be informative to enter the waiting room on some pretence to unobtrusively observe the patient before the consultation begins.

We illustrate the value of these waiting room signs for patients with parkinsonian syndromes, where careful observation is necessary to make a correct diagnosis. We consider the various stages that may precede the actual and formal examination: observing the patient while still seated in the waiting room, waiting to be called upon (when information can be deduced from clothing, posture and behaviour); noting the way patients stand up from a chair when their name is called; examining the first handshake; listening to the breathing and voice patterns; recognising some facial clues during initial pleasantries; and finally, monitoring the way patients walk towards your office (Video 1 ). Table 1 offers a summary of the various signs that can be observed during these respective stages. We elaborate briefly on several persuasive examples below.

\section{The patient sitting in the waiting room}

\section{Behaviour}

A behaviour commonly seen in patients with parkinsonism is concealing a tremulous hand in a pocket, under a handbag or even by sitting on one hand (Video 2 Segment 1). We have also seen this behaviour in children with chorea and in alienlimb phenomenon in corticobasal syndrome (Video 2 -Segment 2). The opposite typically occurs in patients with a functional or psychogenic tremor where every effort is made to exhibit the tremor. The tension of waiting to see the doctor in a crowded waiting room can often bring out restless and jerky fidgety movements caused by L-DOPA therapy. A slowness and awkwardness in getting an identification or a health card from the wallet or handbag also suggests motor impairment. Patients with parkinsonism usually sit motionless, speaking in lowered tones to the spouse or friend. Another behaviour we have noticed is the practicing of finger 
tapping in those hoping to make a good impression on their physician during the formal examination.

Patients who fall asleep while waiting are relatively unusual but when present it may indicate excessive daytime somnolence, a green flag for cognitive impairment, a non-motor symptom of $\mathrm{PD},{ }^{12}$ possibly aggravated by use of sedative medication or the sedating effects of antiparkinsonian medication, particularly dopamine agonists. ${ }^{13}$ Sleeping patients also raises the issue of other contributing sleep disorders, such as obstructive sleep apnoea or rapid eye movement behavioural disorder which would need to be pursued on further questioning in the examination room. Cognitive dysfunction in patients with progressive supranuclear palsy (PSP) or corticobasal syndrome may present with disinhibition (recklessness or inappropriate behaviour) or apathy. Sweating when no one else is even hot in the waiting room is a clue that autonomic dysfunction may be present.

\section{Sitting posture}

A considerable amount of information can be obtained just by examining the patient's posture while sitting in the waiting room. One of the most informative images is the profound stillness of parkinsonism patients compared with the other patients in the waiting room. Another typical feature in these patients is the diminished social movements: less agile or absent gesticulations with the arms while maintaining a conversation, typically in an asymmetrical fashion in persons with Parkinson's disease. The staring immobile face with absent blinking and reduced eye movements suggests PSP. A Pisa syndrome (marked lateral leaning to one side) may be found and many patients slump to the side of greater physical handicap when waiting to be seen (Video 3). Retrocollis is occasionally seen in PSP ${ }^{14}$ and antecollis can be seen in MSA. ${ }^{15} \mathrm{~A}$ dropped neck may be seen sometimes in association with Parkinson's disease and may have a neuromuscular cause.

\section{Clothing and accessories}

Patients who hold a handkerchief or a washcloth often complain of drooling of saliva. Loose collars or compression stockings may signal dysautonomia, as in e.g. patients with MSA. Impaired vertical eye movements, axial rigidity, retrocollis and executive dysfunction often lead to messy eating (the "dirty tie sign" syndrome). ${ }^{16}$ Patients wearing sandals in cold weather may point to the presence of ankle swelling or a dystonic foot. Bruises of the face or the presence of a plaster cast suggest postural instability and falls. Finally, seeing a wheelchair with a patient who is referred to you for a relatively recent onset of parkinsonism is a red flag for PD, and rather suggest a form of atypical parkinsonism ("the wheelchair sign"). ${ }^{17}$ 
A lopsided belt and unfastened buttons may also suggest fine motor impairment in parkinsonism. Follow-up cases with established parkinsonism might prefer comfortable, practical clothing, such as Velcro shoes, no ties or cufflinks.

\section{Calling the patient}

\section{Initial reaction}

The response to calling the patients may already be informative. Patients who seem largely unconcerned when their name is called may have depression or apathy. Patients who are not present in the waiting room when called in, because they had to go use the toilet, might have a relate bladder or bowel disturbance.

The patient may rise slowly from the chair, requiring multiple attempts, with support of the arms, and sometimes falling back. PSP patients may respond very impulsively and rise very rapidly from their chair (and then fall back into it, due to their postural instability that is particularly pronounced in the backward direction), an observation that has been termed the "rocket sign". 18

\section{Initial pleasantries}

\section{Handshake}

MSA patients may present with very cold, dusky hands, reflecting their autonomic dysfunction ("the cold hand sign"). ${ }^{19}$ Patients with severe dominant limb dysfunction may offer the left hand when the examiner goes to shake their right. A frozen hand in a fixed flexed position may be a sign of MSA. The inability to use the right hand for a handshake can also be secondary to profound mixed dysfunction in corticobasal syndrome, namely a combination of dystonia, apraxia and myoclonus. Sometimes patients with functional movement disorders will seem to "protect" or not be able to use their dominant hand in response to the examiner's outstretched hand. A clumsy handshake may be seen due to levodopa-induced dyskinesia. Also, action tremor and dysmetria (as in patients with cerebellar disease) may be noticeable when the patient reaches out prior to the handshake. Rarely a grasp reflex is present in PSP (when the patient has difficulty letting your hand go after the handshake). Alternatively, patients with frontal dysfunction may grasp the shaking hand excessively tightly and maintain a prolonged grip even in the absence of a grasp response.

\section{Speaking and breathing}

The most straightforward observation is the typical hypophonia associated with parkinsonism. However, when patients referred for a workup of their parkinsonism present with a piping nasal, high-pitched dysarthophonia or a stridor, then a 
diagnosis of MSA should be considered. ${ }^{20,21}$ Patients with PSP have a slow, deeper pitched, growling slurred speech, that can be recognized even on the telephone. Constant groaning, often in combination with the characteristic spastic-hypokinetic dysarthria, is another characteristic of PSP. Laryngeal dystonia presents with a characteristic strained speech or, less often, a breathy speech. Breathing irregularities such as inspiratory sighs or rapid shallow breathing may also be observed.

\section{Facial clues}

The observation of facial features is very informative in a movement disorders setting. A masked face with reduced eye blinking suggests parkinsonism. An "oily" appearance of the skin of the face and forehead, sometimes accompanied by a red scaly rash, can signal the presence of a seborrhoeic dermatitis in patients with PD. This excessive seborrhoea is thought to contribute to the typical musky smell that can be noticed in PD patients (spouses may have noted this change in smell in the patient many years earlier). ${ }^{22}$ Overactive frontalis and procerus muscles with "staring fixed eyes" suggests PSP, but it can also be seen in MSA. ${ }^{16} \mathrm{~A}$ mild freezing of the face on first glance is a fairly common feature in PD patients. MSA patients treated with levodopa may have facial dystonia. ${ }^{15}$ Involuntary eyelid closure may suggest PSP or be a consequence of L-DOPA treatment in PD.

One example that combines some of the clues mentioned above can allow for a diagnosis of the Richardson-syndrome form of PSP (PSP-RS). When the examiner stands above and to the side of the seated patient extending their arm to welcome a handshake, the PSP patient will not make the normal quick upward saccade to allow eye to eye contact but will slowly raise the head and to the side, eventually making eye contact with the examiner. This is combined with a slow elevation of their own arm and a "Hello Dr..." in a gravely, slightly nasal voice.

\section{Escorting the patient to the observation room}

Observation of gait should start when escorting the patient to the examination room. A wide range of abnormalities can be noted, such as the slow and shuffling gait in PD, a wide-based gait in a range of disorders (including cerebellar and sensory ataxia), truncal abnormalities (such as camptocormia in PD), and reductions in arm swing (with flexion at the elbow). It is useful to engage the patient in small talk before entering the examination room; the risk of future falling is increased for persons who stop walking while talking. ${ }^{23}$ Recklessness may also be observed (inappropriately fast walking despite clear balance problems), and this may suggest PSP, frontal dementia, or sometimes cerebellar ataxia. Observing patients as they walk towards the examination room is also a good moment to note how the patient handles any walking aids - many patients tend to use these inappropriately, for 
example by simply holding a walking frame up into the air, rather than using it for actual support. A notable absence of any assistive device in a patient with marked gait disability or postural instability is also important - some patients are too proud or ashamed to resort to using them, despite an obvious clinical need. Walking in a wide hospital corridor is not ideal for observing freezing of gait, but this can sometimes be seen when patients initiate gait from sitting or while turning into your direction after having risen from their chair, or while crossing the door frame upon entering the examination room, or when approaching their seat in the examination room. Even if you don't come out to watch the walk, you may notice that you are holding the door open a little longer for the parkinsonian patient than for most other patients. Several clues may signal a functional disorder, such as exaggerated efforts, extreme slowness, a "walking on ice" pattern, knee buckling ${ }^{24}$ and the "huffing and puffing" sign. ${ }^{25}$ We recently observed a particular example of exaggerated effort, in a patient with a functional gait disorder who left a marked imprint of her dragging feet onto a linoleum of the corridor (Figure 1).

\section{Variability over time}

There is value in observing the patients entering or especially leaving the clinic at a time when they believe they are no longer being examined (at this time there may be a pronounced change and even complete resolution of the marked features that were evident on walking from the waiting room to the exam room and during the assessment). Significant variability is an important clue for functional movement disorders (this includes functional parkinsonism, or patients with PD and a superimposed layer of functional signs). ${ }^{26}$ However, PD patients may also display a markedly different behavior over even a short period of time due to levodoparelated fluctuations. Patients may arrive in an off or on state but by the time they are brought to the examination room they may be in the opposite state.

\section{Discussion}

Neurology, and particularly the field of movement disorders and parkinsonism, are arguably among the clinically most refined branches of medicine, where a clinical gaze can make an important difference to diagnostic accuracy. We argue that many precious clinical observations can be made before the traditional formal neurological examination begins. Indeed, a spot diagnosis of e.g. PD can be made even in busy public places, ${ }^{27}$ and we discuss here that the waiting room is another rich source of "free" clinical information. Even browsing through the hand-written registration form can be informative, allowing for a distinction between parkinsonism and indeterminate tremor. And we have highlighted the added value of comparing what is seen in the examination room with what is observed in the waiting room. 
Obviously, uncontrolled observations in the waiting room should never replace a thorough history taking and neurological examination, which continue to be the cornerstone of any careful clinical approach. ${ }^{28}$ Our point is merely that an early look at your patients may provide important, sometimes invaluable clues that should not be disregarded. This, obviously, does not equate to providing a diagnosis while the patient is still shaking the doctor's hand. Getting a head start on the patient's illness may provide more time in the appointment to identify the reasons for referral, to carefully evaluate the patient's priorities, and to discuss the nature and impact of the patient's symptoms as well as their management.

Note that the list offered in Table 1 is not intended to be all-inclusive. We are primarily specialists in movement disorders, and this explains our natural bias for signs and diagnoses in this field. We are well aware that a high degree of specialization carries the risk of "tunnel vision", ${ }^{29}$ and we challenge the readers to come up with a similar list in their own field. For example, a neuromuscular expert could consider looking for a receding hairline, temporal atrophy and ptosis in myotonic dystrophy, or for a myotonic grip. ${ }^{30}$ Also, a dropped head might suggest muscular weakness in myasthenia gravis, motor neuron disease or myopathy. ${ }^{31,32}$ Similarly, neuro-ophthalmologists could consider looking for sunglasses ${ }^{33}$ for the same reason epileptologists could look for teddy bears in the waiting room (both may suggest the presence of a functional neurological disorder, although this could be misleading in the case of organic blepharospasm). ${ }^{6}$

The neurological examination and the possibility of an Augenblick Diagnose ("diagnosis in the blink of an eye") is one of the things that particularly fuels the enthusiasm for clinical neurology among medical students and residents. We hope that our short report will further drive that excitement.

\section{Key-Points:}

- Neurology, and particularly the field of movement disorders and parkinsonism, are arguably among the clinically most refined branches of Medicine.

- Being a "meeter" instead of a "buzzer" might be advantageous.

- A significant number of valuable neurological signs are readily available in the waiting room.

- A thourough neurological examination is still the cornerstone for diagnosis in movement disorders, and parkinsonian syndromes in particular.

\section{Acknowledgements}


RA would like to thank to Dr. João Carvalho for alerting him to the behaviour of PD patients holding a resting tremor with the unaffected limb. Prof. Bas Bloem was supported by a research grant of the Parkinson's Foundation.

\section{Author roles}

Rui Araújo contributed with the review of the existing literature, provided Video 2, conceptualized an early framework for the manuscript and drafted an early version of the paper. Bart van de Warrenburg provided significant input to early versions of the manuscript, as well as review and critique of later versions. Anthony Lang and Andrew Lees provided significant input to both early and final versions of the manuscript, adding extensive examples drawn from their own personal experience. Bastiaan Bloem provided the idea for the manuscript, contributed to its early design, added several examples from his own personal experience, reviewed the final versions of the manuscript, provided video 1 and the image for Figure 1. He also takes responsibility for the integrity of the data and the accuracy of the data analysis.

Patient consent was obtained for the publication of the videos.

\section{References}

1. Bateman-House, A., \& Fairchild, A. (2008). Medical Examination of Immigrants at Ellis Island. Virtual Mentor, 10(4), 235.

2. Peschel, R. E., \& Peschel, E. (1989). What physicians have in common with Sherlock Holmes: discussion paper. Journal of the Royal Society of Medicine, 82(1), 33.

3. Verghese, A. A doctor's touch, TED. Available online in https://www.ted.com/talks/abraham verghese a doctor s touch/transcript

4. Doyle, A. C. (1994). The Boscombe Valley Mystery (pp. 90-112). Macmillan Education UK.

5. Parkinson J. An essay on the shaking palsy. London: Sherwood, Neely and Jones; 1817. Reprinted in: Neuropsychiatric classics. J Neuropsychiatry Clin Neurosci2002;14:223-236.

6. Burneo, J. G., Martin, R., Powell, T., Greenlee, S., Knowlton, R. C., Faught, R. E., ... \& Kuzniecky, R. I. (2003). Teddy bears: an observational finding in patients with nonepileptic events. Neurology, 61(5), 714-715.

7. Manfredi, M., Teive, H. A., Pedace, F., Andrade, L. A. F., Ferraz, H. B., Sa, D. S., \& Currà, A. (2003). C. David Marsden and Rolex sign. Neurological Sciences, 24(1), 4546.

8. Nutt, J. G., Bloem, B. R., Giladi, N., Hallett, M., Horak, F. B., \& Nieuwboer, A. (2011). Freezing of gait: moving forward on a mysterious clinical phenomenon. The Lancet Neurology, 10(8), 734-744.

9. Cohen, S. C., Leckman, J. F., \& Bloch, M. H. (2013). Clinical assessment of Tourette syndrome and tic disorders. Neuroscience \& Biobehavioral Reviews, 37(6), 997-1007.

10. Gupta, A., \& Lang, A. E. (2009). Psychogenic movement disorders. Current opinion in neurology, 22(4), 430-436.

11. Whitaker, P. (2014). Is your GP a buzzer or a meeter? Sometimes, a diagnosis starts in the waiting room. Newstatesman. Available online in 
http://www.newstatesman.com/lifestyle/2014/06/your-gp-buzzer-or-meetersometimes-diagnosis-starts-waiting-room

12. Poewe, W. (2008). Non-motor symptoms in Parkinson's disease. European Journal of Neurology, 15(s1), 14-20.

13. Paus, S., Brecht, H. M., Köster, J., Seeger, G., Klockgether, T., \& Wüllner, U. (2003). Sleep attacks, daytime sleepiness, and dopamine agonists in Parkinson's disease. Movement Disorders, 18(6), 659-667.

14. Burn, D. J., \& Lees, A. J. (2002). Progressive supranuclear palsy: where are we now?. The Lancet Neurology, 1(6), 359-369.

15. Edwards, M. J., Stamelou, M., Quinn, N., \& Bhatia, K. P. (2016). Parkinson's disease and other movement disorders. Oxford University Press.

16. Quinn, N. (1995). Parkinsonism--recognition and differential diagnosis. BMJ: British Medical Journal, 310(6977), 447

17. Köllensperger, M., Geser, F., Seppi, K., Stampfer-Kountchev, M., Sawires, M., Scherfler, C., ... \& Pellecchia, M. T. (2008). Red flags for multiple system atrophy. Movement Disorders, 23(8), 1093-1099

18. Warren, N. M., \& Burn, D. J. (2007). Progressive supranuclear palsy. Practical neurology, 7(1), 16-23.

19. Klein, C., Brown, R., Wenning, G., \& Quinn, N. (1997). The "cold hands sign" in multiple system atrophy. Movement disorders, 12(4), 514-518.

20. Wenning, G. K., Colosimo, C., Geser, F., \& Poewe, W. (2004). Multiple system atrophy. The Lancet Neurology, 3(2), 93-103.

21. Quinn, N. P. (2005). How to diagnose multiple system atrophy. Movement disorders, 20(S12), S5-S10.

22. Morgan, J. (2016). Joy of super smeller: sebum clues for PD diagnostics. The Lancet Neurology, 15(2), 138-139.

23. Lundin-Olsson, L., Nyberg, L., \& Gustafson, Y. (1997). Stops walking when talking as a predictor of falls in elderly people. Lancet, 349(9052), 617.

24. Stone, J., Carson, A., \& Sharpe, M. (2005). Functional symptoms and signs in neurology: assessment and diagnosis. Journal of Neurology, Neurosurgery \& Psychiatry, 76(suppl 1), i2-i12.

25. Laub, H. N., Dwivedi, A. K., Revilla, F. J., Duker, A. P., Pecina-Jacob, C., \& Espay, A. J. (2015). Diagnostic performance of the "huffing and puffing" sign in functional (psychogenic) movement disorders. Movement disorders clinical practice, 2(1), 2932.

26. Wissel, B. D., Dwivedi, A. K., Merola, A., Chin, D., Jacob, C., Duker, A. P., ... \& Lang, A. E. (2018). Functional neurological disorders in Parkinson disease. J Neurol Neurosurg Psychiatry, jnnp-2017.

27. Kempster, P. A., Hurwitz, B., \& Lees, A. J. (2007). A new look at James Parkinson's Essay on the Shaking Palsy. Neurology, 69(5), 482-485.

28. Aminoff, M. J. (2017). The Future of the Neurologic Examination. JAMA neurology, 74(11), 1291-1292.

29. Bloem, B. R., Voermans, N. C., Aerts, M. B., Bhatia, K. P., van Engelen, B. G. M., \& van de Warrenburg, B. P. (2016). The wrong end of the telescope: neuromuscular mimics of movement disorders (and vice versa). Practical neurology, practneurol-2015.

30. Machuca-Tzili, L., Brook, D., \& Hilton-Jones, D. (2005). Clinical and molecular aspects of the myotonic dystrophies: a review. Muscle \& nerve, 32(1), 1-18.

31. Lomen-Hoerth, C., Simmons, M. L., Dearmond, S. J., \& Layzer, R. B. (1999). Adultonset nemaline myopathy: Another cause of dropped head. Muscle \& nerve, 22(8), 1146-1150.

32. Goh, K. J., Wong, K. T., \& Tan, C. T. (2000). Myopathic dropped head syndrome: a syndrome of mixed aetiology. Journal of clinical neuroscience, 7(4), 334-336. 
33. Bengtzen, R., Woodward, M., Lynn, M. J., Newman, N. J., \& Biousse, V. (2008). The "sunglasses sign" predicts nonorganic visual loss in neuro-ophthalmologic practice. Neurology, 70(3), 218-221. 
Table 1. Waiting room signs in the context of parkinsonism

\begin{tabular}{|c|c|}
\hline \multicolumn{2}{|l|}{ The patient sitting in the waiting room } \\
\hline \multicolumn{2}{|l|}{ Behavior } \\
\hline $\begin{array}{l}\text { Hiding one arm under jacket, in pocket or } \\
\text { holding one limb with the healthy } \\
\text { counterpart, or sitting on the upper limbs }\end{array}$ & $\begin{array}{l}\text { Asymmetrical tremor (PD), levodopa- } \\
\text { induced dyskinesias, alien limb (CBS) }\end{array}$ \\
\hline Profound stillness, speaking quietly & Parkinsonism \\
\hline Restlessness, dyskinesias & $\begin{array}{l}\text { Parkinsonism, drug-induced parkinsonism } \\
\text { with akathisia }\end{array}$ \\
\hline $\begin{array}{l}\text { Awkwardness in getting identification card } \\
\text { from wallet/handbag }\end{array}$ & Fine motor impairment \\
\hline Practising finger tapping & Seasoned PD patients \\
\hline Sleeping & $\begin{array}{l}\text { Dopamine agonists, sedative medication, } \\
\text { poor night-time sleep quality }\end{array}$ \\
\hline Sweating & $\begin{array}{l}\text { Autonomic dysfunction (MSA), PD possibly } \\
\text { experiencing non-motor off symptoms }\end{array}$ \\
\hline Anxiety & $\begin{array}{l}\text { Possibility of a non-motor off in PD, drug- } \\
\text { induced parkinsonism }\end{array}$ \\
\hline \multicolumn{2}{|l|}{ Sitting posture } \\
\hline Pisa syndrome & MSA, or agonist-induced in PD \\
\hline Retrocollis & PSP, recessive parkinsonism \\
\hline Antecollis* & MSA, or late-stage PD \\
\hline Torticollis & Dystonia, late-stage parkinsonism \\
\hline \multicolumn{2}{|l|}{ Clothing and accessories } \\
\hline Handkerchief & Drooling (parkinsonism, dementia) \\
\hline Loose collars / compression stockings & Dysautonomia (MSA) \\
\hline $\begin{array}{l}\text { Messy clothing ("dirty tie sign"), unfastened } \\
\text { button, lopsided belt, practical clothing }\end{array}$ & $\begin{array}{l}\text { PSP, fine motor impairment, longstanding } \\
\text { parkinsonism }\end{array}$ \\
\hline Injuries & $\begin{array}{l}\text { Early and marked postural instability } \\
\text { (atypical parkinsonism), particularly when } \\
\text { combined with recklessness (PSP) }\end{array}$ \\
\hline "Wheelchair sign" ** & $\begin{array}{l}\text { Early and marked postural instability with } \\
\text { falls (atypical parkinsonism) }\end{array}$ \\
\hline Sandals worn in cold weather & $\begin{array}{l}\text { Oedema due to dopamine agonists or } \\
\text { amantadine }\end{array}$ \\
\hline \multicolumn{2}{|l|}{ Calling the patient } \\
\hline \multicolumn{2}{|l|}{ Rising from chair } \\
\hline $\begin{array}{l}\text { Slow, multiple attempts, may require arm } \\
\text { assistance } * * *\end{array}$ & $\begin{array}{l}\text { Longstanding PD, early in disease course in } \\
\text { atypical parkinsonism }\end{array}$ \\
\hline $\begin{array}{l}\text { Rapid rising, with subsequent fall back into } \\
\text { the chair ("rocket sign") }\end{array}$ & PSP \\
\hline \multicolumn{2}{|l|}{ Initial pleasantries } \\
\hline \multicolumn{2}{|l|}{ Handshake } \\
\hline Cold hands, fixed flexed position & MSA \\
\hline $\begin{array}{l}\text { Moving the head to make eye contact with } \\
\text { slow elevation of the arm }\end{array}$ & PSP-RS \\
\hline Grasping **** & Dementia \\
\hline Dysmetria / action tremor & Additional ataxia (MSA) \\
\hline
\end{tabular}




\begin{tabular}{|c|c|}
\hline \multicolumn{2}{|l|}{ Speaking and breathing } \\
\hline Hypophonia & Parkinsonism \\
\hline Quivering, high-pitched dysarthria & MSA \\
\hline Growling dysarthria & PSP \\
\hline Constant groaning & PSP \\
\hline Stridor & MSA, laryngeal dystonia \\
\hline Inspiratory sighs & MSA \\
\hline Cheyne-Stokes respiration & Low cardiac output in vascular parkinsonism \\
\hline \multicolumn{2}{|l|}{ c) Facial clues } \\
\hline Overactive frontalis muscles - "staring eyes" & PSP, MSA \\
\hline Reduced blinking rate & Parkinsonism \\
\hline Dystonia of the orofacial muscles & WD, NBIA, MSA/PSP on levodopa \\
\hline \multicolumn{2}{|c|}{ Escorting the patient to the observation room } \\
\hline Slow, shuffling, freezing, camptocormia & Parkinsonism \\
\hline Wide-based gait & Ataxia, atypical parkinsonism \\
\hline Narrow-based gait, or even leg scissoring & PD, spasticity \\
\hline Apraxic, "magnetic" & Normal-pressure hydrocephalus \\
\hline Reduced arm swing & $\begin{array}{l}\text { Parkinsonism, shoulder impairment (e.g. } \\
\text { orthopaedic) including frozen shoulder seen } \\
\text { in PD }\end{array}$ \\
\hline Walking aids/assistive device & Inappropriate use \\
\hline Holding the door for too long & Parkinsonism \\
\hline Extreme slowness, effort-related behavior & Functional disorders \\
\hline Significant variability & $\begin{array}{l}\text { Functional disorders, motor fluctuations in } \\
\text { levodopa-treated PD patients }\end{array}$ \\
\hline
\end{tabular}

* Needs to be separated from dropped head syndrome due to weakness seen in neuromuscular disorders, such as MG, MND, myopathy or polymyositis.

** Wheelchair sign: patient dependent in under 10 years after disease onset. ${ }^{17}$

*** Proximal leg weakness should also be considered.

**** May resemble grip myotonia in myotonic dystrophy.

Legend: PD: Parkinson's Disease, CBS: corticobasal syndrome, RLS: restless leg syndrome, MSA: multiple system atrophy, PSP: progressive supranuclear palsy, WD: Wilson's Disease; NBIA: neurodegeneration with brain iron accumulation. 


\section{Videos}

Video 1. Illustration of how waiting room signs can be observed. The process starts as the patient arrives, in this case showing festination in a Parkinson patient as he approaches his chair. Rest tremor is another observable feature (shown here for two patients sitting in the waiting room). Slowness upon rising from the chair, and a hypokinetic gait with a reduced arm swing can be seen as the patient is escorted into the examination room.

Video 2. Segment 1: PD patient with asymmetrical rest tremor, holding a tremulous limb with the least affected one. Segment 2: Patient with corticobasal syndrome, holding the arm with an alien limb phenomenon.

Video 3. Patient with MSA demonstrating a Pisa syndrome.

\section{Figure}

Figure 1: "Stripes on the floor" as seen in a patient with a functional gait disorder, displaying effort-related behaviour, with footsteps imprinted onto the linoleum of the corridor due to excessive dragging of the feet. 


\section{Full financial disclosures for the previous 12 months}

Dr. Araújo received salary from Centro Hospitalar e Universitário de Coimbra for his work as a neurology resident.

Dr. Bart van Warrenburg has received research support from ZonMW, Hersenstichting, Radboud university medical centre, and Biobalst Pharma.

Dr. Lang has served as an advisor for Abbvie, Acorda, Biogen, Bristol Myers Squibb, Janssen, Sun Pharma, Kallyope, Merck, Paladin, Theravance, and Corticobasal Degeneration Solutions; received honoraria from Sun Pharma, Medichem, Medtronic, AbbVie and Sunovion; received grants from Brain Canada, Canadian Institutes of Health Research, Corticobasal Degeneration Solutions, Edmond J Safra Philanthropic Foundation, Michael J. Fox Foundation, the Ontario Brain Institute, National Parkinson Foundation, Parkinson Society Canada, and W. Garfield Weston Foundation; received publishing royalties from Elsevier, Saunders, Wiley-Blackwell, Johns Hopkins Press, and Cambridge University Press.

Prof. Andrew Lees Is funded by the Reta Lila Weston Institute of Neurological Studies, University College London, Institute of Neurology CONSULTANT: Britannia Pharmaceuticals (Genus), BIAL Portela. GRANTS/ RESEARCH SUPPORT: Frances and Renee Hock Fund. HONORARIA (including Advisory Board Meetings): Profile Pharma, BIAL, Roche, Britannia, UCB, Nordiclnfu Care, NeuroDerm, Decision Resources, Windrose Consulting Group. INTELLECTUAL PROPERTY RIGHTS: Nothing to disclose. OWNERSHIP INTEREST (e.g. Stocks): Nothing to disclose. ROYALTY: Nothing to disclose. SALARY: UCL

Prof. Bloem currently serves as Associate Editor for the Journal of Parkinson's disease, serves on the editorial of Practical Neurology, has received honoraria from serving on the scientific advisory board for Zambon, Abbvie, UCB and Kyowa Kirin, has received fees for speaking at conferences from AbbVie, Zambon and Bial, and has received research support from the Netherlands Organization for Scientific Research, the Michael J Fox Foundation, UCB, Abbvie, the Stichting Parkinson Fonds, the Hersenstichting Nederland, the Parkinson's Foundation, Verily Life Sciences, the Topsector Life Sciences and Health, and the Parkinson Vereniging. 